\title{
Prevalence and Correlates of Herbal Medicine Use among Women Seeking Care for Infertility in Freetown, Sierra Leone
}

\author{
Peter Bai James $\mathbb{D}^{1,2}$ Lexina Taidy-Leigh,, Abdulai Jawo Bah,, Joseph Sam Kanu, \\ Jia Bainga Kangbai, ${ }^{4,5}$ and Stephen Sevalie ${ }^{6}$ \\ ${ }^{1}$ Faculty of Pharmaceutical Sciences, College of Medicine and Allied Health Sciences, University of Sierra Leone, Freetown, Sierra Leone \\ ${ }^{2}$ Australian Research Centre in Complementary and Integrative Medicine, Faculty of Health, University of Technology Sydney, Ultimo, \\ Sydney, NSW 2007, Australia \\ ${ }^{3}$ Faculty of Basic Medical Sciences, College of Medicine and Allied Health Sciences, University of Sierra Leone, Freetown, Sierra Leone \\ ${ }^{4}$ Center for International Health, University of Munich, Munich, Germany \\ ${ }^{5}$ Department of Environmental Health Sciences, School of Community Health Sciences, Njala University, Bo, Sierra Leone \\ ${ }^{6} 34$ Military Hospital, Freetown, Sierra Leone
}

Correspondence should be addressed to Peter Bai James; jamepeb@yahoo.com

Received 24 October 2017; Revised 6 February 2018; Accepted 18 February 2018; Published 22 April 2018

Academic Editor: Karin Kraft

Copyright (C) 2018 Peter Bai James et al. This is an open access article distributed under the Creative Commons Attribution License, which permits unrestricted use, distribution, and reproduction in any medium, provided the original work is properly cited.

In resource-poor countries where access to infertility care is limited, women may turn to traditional medicine to achieve motherhood. It is unknown whether Sierra Leonean women with such condition use herbal medicine. This study investigates the prevalence and factors associated with herbal medicine use among women seeking care for infertility. This was a questionnairebased cross-sectional study conducted among women seeking care for infertility at various clinics within Freetown, Sierra Leone. Data analysis included Chi-square tests and logistic regression. Out of the 167 women that participated, $36.5 \%$ used herbal medicine for infertility treatment. Women with no formal (AOR 4.03, CL: 1.38-11.76, $p=0.011$ ), primary education (AOR: 6.23, CL: 2.02-19.23, $p=0.001$ ) and those that visited a traditional medicine practitioner (AOR: 20.05, CL: 2.10-192.28, $p=0.009$ ) as well as women suffering from other reproductive health problems (AOR: 2.57, CL: 1.13-5.83, $p=0.024$ ) were more likely to use herbal medicines. Friends and family $(n=57,96.7 \%)$ were the main influencers of herbal medicine use. Only $(n=12) 19.7 \%$ of users disclosed their status to their healthcare provider. Over half $(n=32,52.5 \%)$ could not remember the name of the herb they used. Luffa acutangula $(n=29,100 \%)$ was the herbal medicinal plant users could recall. Herbal medicine use among women seeking care for infertility in Freetown is common. Healthcare providers should be aware of the potential dyadic use of herbal and allopathic medicines by their patients and be knowledgeable about commonly used herbal remedies as well as being proactive in communicating the potential risks and benefits associated with their use.

\section{Introduction}

Infertility is considered a social and public health problem that affects the health and wellbeing of millions of couples worldwide [1]. The World health Organization (WHO) defines infertility as the "failure to conceive after 12 months of regular unprotected sexual intercourse in the absence of known reproductive pathology [2]". Globally, in the past two decades, the absolute number of couples affected by infertility has increased from 42.0 million in 1990 to 48.5 million in 2010 [3]. In Sub-Saharan Africa, infertility still receives less attention and is of low priority in the continent's reproductive health agenda $[4,5]$ despite its huge psychosocial and economic impact on individuals, families, and communities $[4,6-8]$. It is believed that increased population growth due to high fertility rate in the region has masked the spotlight infertility deserves. Paradoxically, the prevalence of infertility in certain Sub-Saharan African countries is reported to be more than $30 \%$ [9].

Infertility or childlessness in most developing countries including Africa is gender biased with the female partner often cited as the cause of the problem [10, 11]. In many 
of these communities, women are target of psychological and physical abuse by their families and communities. Such an abuse can be in the form of marital instability, divorce, social isolation stigma, economic deprivation, and intimate partner violence [8, 12-14]. Bearing a child in Africa not only defines womanhood but also brings dignity and respect to the family as well as securing rights of property and inheritance [13]. It also serves to guarantee the continuation of the family lineage and future social insurance against poverty in a region where social security schemes during old age are uncommon [15]. Family and societal pressure to conceive and the increasing odds of reduced fertility due to aging [16], together with the inability to access high cost conventional medical therapies such as in vitro fertilization (IVF) and assisted reproductive technology (ART) $[10,17,18]$, may influence a woman's decision to seek complementary or alternative health approaches such as herbal therapy in order to conceive.

Herbal medicine is the prevalent form of traditional and complementary medicine use in Sub-Saharan Africa [19-21]. Reasons for its popularity is attributed to its low cost, accessibility, alignment with patient's cultural and religious values, and perceived efficacy and safety as well as dissatisfaction with conventional healthcare [22-27]. Despite the popularity of traditional and complementary medicine, evidence of its safety and efficacy still remains inconclusive. As with most countries in Africa, traditional medicine use in Sierra Leone is common with considerable amount of the population using it to treat various health conditions such malaria, diarrhea, and respiratory infections and hypertension [20, 28-31].

Unorthodox fertility services are widespread in Africa and are often provided by traditional medicine practitioners [32]. While many studies outside of Africa have looked at traditional and complementary health approaches utilized by women seeking infertility care [33-37], only few studies across Africa have focused on this issue with relatively high use reported in these studies. A Ugandan study reported $76.2 \%$ prevalence of herbal medicine use among women seeking infertility care [38], while a Nigerian study reported that more than two-thirds of infertile couples (69\%) seek care from a traditional complementary medicine practitioner [32]. Another study from Rwanda reported that $11 \%$ of the 277 women who took part in the study visited a traditional healer [39]. Even though herbal medicine use is reported to be widespread in Sierra Leone [29-31, 40], it is unknown whether women seeking infertility care use herbal medicines for their condition. It is against this background that this study was conducted to determine the prevalence and factors associated with herbal medicine use among women seeking care for infertility in Freetown, Sierra Leone.

\section{Methodology}

2.1. Study Design and Population. A quantitative crosssectional study was performed among women seeking fertility care at various clinics within the municipality of Freetown, Sierra Leone. The study was done between the months of September 2016 and November 2016. Women between the ages of 18-49 years who were seeking fertility care, of various ethnic groups and religious backgrounds, were eligible to participate. Severely ill women were excluded from the study.

2.2. Study Setting. Area selected for this study was Western Area Urban, Freetown. Six maternity clinics providing fertility care to patients were purposefully selected. We purposefully chose the cited clinics because they are the ones providing fertility care to women in Freetown. These health facilities include Mary-Immaculate Maternity Clinic, Women's Healthcare Centre, Family Medical Care Centre, Marie-Stopes clinics at the western and eastern parts of Freetown, and 34 Military Hospital. Selection of participants from the various clinics was done through consecutive sampling and the target number in each clinic was through the proportional representation based on the attendance rate at each facility.

2.3. Sample Size and Determination. A target sample of 192 women was determined using the formula for sample size calculation for cross-sectional study; that is, $n=z^{2} p q / d^{2}$, where $n$ is required minimum sample size, $z$ is value of test statistics (1.96), $q$ is probability of those not using herbs, that is, $(1-p), d$ is degree of accuracy or standard error (0.06), and $p$ is estimated proportion of use of herbal medicine among women seeking fertility care. We assumed $p=76.2 \%$ based on a similar study conducted in Uganda [38].

2.4. Study Questionnaire. The study questionnaire was developed based on available literature from similar studies done in Uganda [38], United Kingdom [41], Turkey [37], Australia [42], and Lebanon [35]. The drafted questionnaire was pretested among 15 women having fertility issues whose data were excluded in the final analysis. Based on the feedback from this pretest, changes were made on the initial draft which was then used in the actual study. The study questionnaire comprised four (4) sections. The first section consists of the sociodemographic characteristics of the participant such as age, tribe, religion, marital status, and education level. The second section looked at the general and reproductive health status of the participant. The third section consists of questions regarding participants use of herbal medicine. The fourth and final section looked at the general perception of herbal medicine among respondents. Herbal medicines considered in this study were based on the WHO definition which includes herbs (such as leaves, flowers, fruits, seeds, stems, wood, bark, roots, or other plant parts which may be entire, fragmented, or powdered), herbal materials (such as fresh juices, gums, oils, dry powders obtained by procedures like steaming, roasting, etc.), herbal preparations (finished herbal products including powdered herbal materials or extracts, tinctures, and oils of herbal materials, and also those made in the form of beverages), and finished herbal products that contain active ingredients as parts of plants, or other plant materials or combinations [43]. Herbal medicine users were defined as women in the inclusion group that reported the use of herbal medicine for infertility for the past twelve months administered orally and/or through any other route of drug administration. 
2.5. Data Collection. The data was collected through faceto-face interview for participants who were illiterate as well as a self-administered format for women who can read and write. The purpose of the study was explained to the patients and those who consented were interviewed. Participants were assured of their confidentiality and given the liberty to opt out of the study at any time while filling the form or being interviewed. A consent form was signed to confirm their willingness to participate in the study. To help minimize social desirability bias, data collectors were extensively trained on the rubrics of data collection process such as not being judgmental, being neutral, and avoiding asking questions that can influence participant response [44].

2.6. Data Analysis. Data analysis was done using SPSS Package version 24 (SPSS, Inc; Chicago). Descriptive statistics were used to calculate frequency counts and percentages for categorical variables and mean standard deviation for continuous variables. Chi-square and Fischer exact two tailed tests were used to determine the association between herbal medicine use (dependent variable) and demographic and health-related variables (covariates). In order to adjust for possible confounders and evaluate independent effects of each independent variable on the outcome variable (herbal medicine use), univariate analysis was conducted and demographic and health-related variables that show statistically significant association were then entered into multivariate logistic model. Differences were considered statistically significant if the $p$ value was less than 0.05 .

2.7. Ethical Clearance. Ethical clearance for this study was sought from the Research and Ethics Committee of COMAHS-USL.

\section{Results}

3.1. Sociodemographic and Health-Related Characteristics of Women Seeking Care for Infertility. Out of the 192 approached, 167 agreed to participate, giving a response rate of $89.8 \%$. 88 participants were between the ages of 20-29 years $(52.7 \%), 110$ married $(65.0 \%), 67$ attained tertiary level of education (40.1\%), and 131 employed (78.4\%), and those with monthly income between 1.5 and 3 million Leones, 127 (76\%), were predominant. Please see Table 1 for more details.

3.2. Association between Sociodemographic and HealthRelated Factors and Herbal Medicine Use among Women Seeking Care for Infertility. Based on the results from data analysis, educational status $(p<0.001)$ and monthly income $(p<0.001)$ and those without other reproductive health problems apart from infertility $(p=0.017)$, those who had previously given birth $(p=0.017)$, those who faced barriers to accessing conventional fertility care $(p<0.001)$, and those who did not visit a traditional medicine practitioner $(p<$ 0.001 ) were shown to have statistically significant association with the use of herbal medicine as seen in Table 2.
3.3. Predictors of Herbal Medicine Use among Women Seeking Care for Infertility. Table 3 presents univariate and multivariate regression analysis of possible predictors of herbal medicine use among women seeking fertility care. Women who had no formal (AOR 4.03, CL 1.38-11.76, $p=0.011$ ) or primary education (AOR: 6.23, CL: 2.02-19.23, $p=0.001$ ) were 4 and 6 times more likely to use herbal medicines than those that attained tertiary education, respectively. Also, women who visited a traditional medicine practitioner (AOR: 20.05, CL: $2.10-192.28, p=0.009$ ) were 20 times more likely to use herbal medicine than those who did not visit a traditional medicine practitioner. In addition, women suffering from other reproductive health problems were almost three times more likely to use herbal medicine than those who did not suffer from other reproductive health problems (AOR: 2.57, CL: 1.13-5.83, $p=0.024)$.

3.4. Pattern of Herbal Medicine Use among Women Seeking Care for Infertility. Based on the analyzed data in Table 4, $36.5 \%$ of the total number of participants $(n=167)$ have used or are currently using herbal medicine for their condition, with the majority (96.7\%) of which doing so due to recommendation by friends and family. Only $47.5 \%$ of participants who used herbal medicine knew the name of the product used and Rabena (Luffa acutangula) was cited as the herbal medicine used. Route of administration was oral (100\%). 11.5\% experienced side effects, majority of which was amenorrhea (42.8\%). A fifth (19.7\%) of participants who used herbal medicine disclosed their status to their healthcare provider. Reasons for nondisclosure to healthcare provider were because the doctor did not ask $(51.0 \%)$ or participants did not think it was necessary (49\%).

\subsection{Perception of Herbal Medicine Use among Women Seeking} Care for Infertility $(n=167)$. Only $1.2 \%$ of the total number of participants $(n=167)$ agreed that herbal medicines are effective for their condition. 53.3\% disagreed that herbal medicines are safer than western medicines for infertility and $46.7 \%$ were not sure. Almost half (46.1\%) agreed that herbal medicines are natural. About $26.3 \%$ also agreed that herbal medicines are beneficial when recommended by healthcare provider and only $1.2 \%$ agreed that it is beneficial when recommended by traditional medicine practitioner or herbalist. Only $3.6 \%$ of the total number of participants agreed that herbal medicine should be integrated into the mainstream healthcare system as in Table 5.

\section{Discussion}

This study presents the first empirical findings in Sierra Leone on traditional medicine use among women seeking conventional fertility treatment. Our study highlights key findings that are worth discussing. First, the use of herbal medicine is common (36.5\%) among women undergoing biomedical infertility care. This prevalence of herbal medicine use is lower than similar studies conducted in Uganda [38] and Lebanon [35] but higher than studies conducted in USA [36], Turkey [37], Jordan [33], Australia [42], and Rwanda [39]. The 
TABLE 1: Sociodemographic and health-related characteristics.

\begin{tabular}{|c|c|c|}
\hline Characteristics & Variables & $N(\%)$ \\
\hline \multirow{3}{*}{ Age group } & $20-29$ years & $88(52.7)$ \\
\hline & $30-39$ years & $78(46.7)$ \\
\hline & $40-49$ years & $1(0.6)$ \\
\hline \multirow{4}{*}{ Tribe } & Mende & $44(26.3)$ \\
\hline & Temne & $39(23.4)$ \\
\hline & Fullah & $12(7.2)$ \\
\hline & Others & $72(43.1)$ \\
\hline \multirow{4}{*}{ Marital status } & Single & $10(6.0)$ \\
\hline & Married & $110(65.0)$ \\
\hline & Cohabitate & $45(26.9)$ \\
\hline & Separated & $2(1.2)$ \\
\hline \multirow{2}{*}{ If married, type of marriage, $n=110$} & Monogamous & $101(91.0)$ \\
\hline & Polygamous & $10(9.0)$ \\
\hline \multirow{2}{*}{ If polygamous, number of wives, $n=10$} & Two wives & $8(80.0)$ \\
\hline & Three wives & $2(20.0)$ \\
\hline \multirow{3}{*}{ Duration of relationship } & $1-5$ yrs & $105(61.7)$ \\
\hline & $6-10$ yrs & $55(32.9)$ \\
\hline & $>10$ yrs & $9(5.4)$ \\
\hline \multirow{4}{*}{ Highest level of education attained } & No formal education & $38(22.8)$ \\
\hline & Primary & $26(15.6)$ \\
\hline & Secondary & $36(21.6)$ \\
\hline & Tertiary & $67(40.1)$ \\
\hline \multirow{2}{*}{ Religion } & Christianity & $80(47.9)$ \\
\hline & Islam & $87(52.1)$ \\
\hline \multirow{4}{*}{ Provider of household income } & Self & $7(4.2)$ \\
\hline & Partner & $47(28.1)$ \\
\hline & Both & $109(65.3)$ \\
\hline & Others (parent or in-laws etc.) & $4(2.4)$ \\
\hline \multirow{2}{*}{ Employment status } & Employed & $131(78.4)$ \\
\hline & Unemployed & $36(21.6)$ \\
\hline \multirow{2}{*}{ Monthly income } & $<1$ million Leones & $40(24.0)$ \\
\hline & 1-3.5 million Leones & $127(76.0)$ \\
\hline \multirow{3}{*}{ Distance from health facility } & $<5 \mathrm{~km}$ & $94(56.3)$ \\
\hline & $5-10 \mathrm{~km}$ & $69(41.3)$ \\
\hline & $>10 \mathrm{~km}$ & $4(2.4)$ \\
\hline \multirow{2}{*}{ Presence of health problem } & Yes & $24(14.4)$ \\
\hline & No & $143(85.6)$ \\
\hline \multirow{7}{*}{ If yes, what type, $n=24$} & Peptic ulcer & $8(33.3)$ \\
\hline & Malaria & $6(25.0)$ \\
\hline & Typhoid fever & $4(16.7)$ \\
\hline & Asthma & $3(12.5)$ \\
\hline & Diabetes & $2(8.3)$ \\
\hline & Sickle cell & $1(4.2)$ \\
\hline & Hypertension & $1(4.2)$ \\
\hline \multirow{2}{*}{ Suffering from reproductive health problems } & Yes & $57(34.1)$ \\
\hline & No & $110(65.9)$ \\
\hline \multirow{6}{*}{ If yes, what type, $n=57$} & Miscarriage & $29(50.9)$ \\
\hline & Vaginal infection & $15(26.3)$ \\
\hline & Sexual transmitted infection & $9(15.8)$ \\
\hline & Fibroid & $2(3.5)$ \\
\hline & Bleeding & $1(1.7)$ \\
\hline & Painful menstruation & $1(1.7)$ \\
\hline
\end{tabular}


TABLE 1: Continued.

\begin{tabular}{|c|c|c|}
\hline Characteristics & Variables & $N(\%)$ \\
\hline \multirow{2}{*}{ If yes, seek help, $n=57$} & Yes & $52(91.2)$ \\
\hline & No & $5(8.8)$ \\
\hline If yes, where did you seek help, $n=57$ & Health facility & $57(100)$ \\
\hline \multirow{2}{*}{ Previously given birth } & Yes & $81(48.5)$ \\
\hline & No & $86(51.5)$ \\
\hline Mean number of children $n=81$ & & $1.5(0.6)^{*}$ \\
\hline \multirow{2}{*}{ Change of partner } & Yes & $15(9.0)$ \\
\hline & No & $152(91.0)$ \\
\hline \multirow{4}{*}{ Suffering from emotional torture from partner or immediate family } & Rejection & $11(6.6)$ \\
\hline & Violence & $5(3.0)$ \\
\hline & Stigma & $6(3.6)$ \\
\hline & None & $145(86.8)$ \\
\hline \multirow{3}{*}{ Cause of infertility } & Witchcraft & $1(0.6)$ \\
\hline & Curse/spell & $1(0.6)$ \\
\hline & Medical causes & $165(98.8)$ \\
\hline \multirow{2}{*}{ Barriers to accessing fertility care } & Yes & $11(6.6)$ \\
\hline & No & $156(93.4)$ \\
\hline \multirow{3}{*}{ If yes, what type of barriers, $n=23$} & Financial & $15(65.2)$ \\
\hline & Distance & $7(30.4)$ \\
\hline & Family & $1(4.4)$ \\
\hline Duration of infertility (months) & & $12.9(11.3)^{*}$ \\
\hline \multirow{2}{*}{ Visit to traditional medicine practitioner } & Yes & $11(6.6)$ \\
\hline & No & $156(93.4)$ \\
\hline
\end{tabular}

${ }^{*}$ Mean (standard deviation). $\$ 1=$ SLL7500 at the time of conducting the study.

difference in utilization rate observed with other countries may be partly due to variation in the availability and access to conventional healthcare and the sociocultural difference on how traditional, complementary, and alternative medicine use is perceived as well as the heterogeneity in the study design and definition of TCAM therapy used [45, 46]. Considering the widespread use of herbal medicine among the Sierra Leonean populace $[47,48]$, and the fact that women in Africa are under enormous pressure to conceive $[5,49]$, the search for answers to their predicament goes beyond seeking conventional care to also include alternative medical care in the form of herbal medicine [50]. In certain instances, TCAM is considered as the first-choice therapy when the cause of infertility is perceived to be nonmedical or nonconventional treatment is considered to be much more effective than conventional therapies [51]. Also, the high cost of conventional therapies such as the use of assisted reproductive technologies (ART) [18] may be a push factor that drives women to consider alternative health approaches such as herbal medicine as their preferred healthcare choice for their condition.

In our study women cited friends and family members as key influencers in their decision to use herbal medicine. In Africa, giving birth to a child defines womanhood and brings public honour and respect to both families [13]. Also, decision-making in Africa regarding reproductive health is often influenced by older family members [52]. As such, the decision to use complementary and alternative medicine is often a family rather than an individual decision. Besides its biomedical cause, infertility, in the African society, is often associated with supernatural and spiritual causes [12, 51] which makes the use of faith healing or a visit to a traditional healer a first-choice health-seeking behavior [12, 32]. Thus, the use of herbal medicine in such circumstances goes beyond its medicinal effect but also for the perceived spiritual, ritualistic, or supernatural power that it possess as dictated by tradition and culture [53]. As such, biomedical fertility care providers should be mindful of these social and cultural dynamics that may influence infertile women health-seeking behavior and routinely enquire about infertile women use of TCAM modalities especially herbal medicine use during consultation. This will create a platform to discuss the risk and benefits of herbal therapy use by their patients and provide appropriate advice. The effectiveness of such discussion requires healthcare providers to be knowledgeable about the commonly used herbal remedies for infertility and their ability to approach such discussion without any prejudice against their patients.

Our finding that herbal medicine users were more likely to be less educated is in line with a similar study conducted in Lebanon [35] but is in contrast with similar studies in Uganda [38] and the UK [41] in which less educated women were less likely to use herbal medicine as well as in the United States in which no significant difference was observed [36]. The high use of herbal medicine among less educated women may be due to less exposure and less knowledge 
TABLE 2: Association between sociodemographic and health-related factors and herbal medicine use among women seeking fertility care.

\begin{tabular}{|c|c|c|c|c|}
\hline Characteristics & Variables & Users $n$ & Nonusers $n$ & $p$ value \\
\hline \multirow{2}{*}{ Age group } & $<30$ years & 27 & 61 & \multirow{2}{*}{0.098} \\
\hline & $\geq 30$ years & 34 & 45 & \\
\hline \multirow{2}{*}{ Religion } & Christianity & 28 & 52 & \multirow{2}{*}{0.694} \\
\hline & Islam & 33 & 54 & \\
\hline \multirow{2}{*}{ Marital status } & Single/separated & 3 & 9 & \multirow{2}{*}{0.389} \\
\hline & Married/cohabitate & 58 & 97 & \\
\hline \multirow{2}{*}{ Type of marriage } & Monogamous & 33 & 68 & \multirow{2}{*}{0.639} \\
\hline & Polygamous & 4 & 6 & \\
\hline \multirow{2}{*}{ Change of partner } & No & 54 & 98 & \multirow{2}{*}{0.393} \\
\hline & Yes & 7 & 8 & \\
\hline \multirow{3}{*}{ Duration of relationship } & $1-5$ yrs & 32 & 71 & \multirow{3}{*}{0.069} \\
\hline & $6-10$ yrs & 23 & 32 & \\
\hline & $>10$ yrs & 6 & 3 & \\
\hline \multirow{4}{*}{ Tribe } & Mende & 15 & 29 & \multirow{4}{*}{0.470} \\
\hline & Temne & 16 & 23 & \\
\hline & Fullah & 2 & 10 & \\
\hline & Others & 28 & 44 & \\
\hline \multirow{4}{*}{ Educational status } & No formal education & 22 & 16 & \multirow{4}{*}{$<0.001$} \\
\hline & Primary & 16 & 10 & \\
\hline & Secondary & 11 & 25 & \\
\hline & Tertiary & 12 & 55 & \\
\hline \multirow{2}{*}{ Employment status } & Employed & 48 & 83 & \multirow{2}{*}{0.953} \\
\hline & Unemployed & 13 & 23 & \\
\hline \multirow{2}{*}{ Monthly income } & $<1$ million Leones & 24 & 16 & \multirow{2}{*}{$<0.001$} \\
\hline & 1-3.5 million Leones & 37 & 90 & \\
\hline \multirow{2}{*}{ Partner with child/children from previous relationship } & Yes & 26 & 30 & 0.066 \\
\hline & No & 33 & 71 & 0.000 \\
\hline & Self & 3 & 4 & \\
\hline Household income provider & Partner & 20 & 27 & 0.383 \\
\hline & Both & 38 & 71 & \\
\hline & Others & 0 & 4 & \\
\hline Duration of infertility & $0-24$ months & 52 & 100 & 0.048 \\
\hline & $>24$ months & 9 & 6 & \\
\hline & $<5 \mathrm{~km}$ & 29 & 65 & \\
\hline Distance from health facility & $5-10 \mathrm{~km}$ & 29 & 40 & 0.084 \\
\hline & $>10 \mathrm{~km}$ & 3 & 1 & \\
\hline Cause of infertility & Supernatural/curse & 2 & 0 & 0.132 \\
\hline Cause or minertinty & Medical & 59 & 106 & 0.132 \\
\hline Presence of health problems & Yes & 8 & 16 & 0.725 \\
\hline & No & 53 & 90 & \\
\hline Presence of other reproductive health conditions other than infertility & Yes & 28 & 29 & 0.017 \\
\hline & No & 33 & 76 & \\
\hline Previously given birth & Yes & 37 & 44 & 0.017 \\
\hline & No & 24 & 62 & \\
\hline Reported emotional torture & Yes & 10 & 12 & 0.351 \\
\hline Keported emotomar torture & No & 51 & 94 & 0.501 \\
\hline Barrier to accessing conventional fertility care & Yes & 34 & 30 & $<0.001$ \\
\hline & No & 27 & 76 & \\
\hline Visit to traditional medicine practitioner & Yes & 10 & 1 & $<0.001$ \\
\hline & No & 51 & 105 & \\
\hline
\end{tabular}


TABLE 3: Predictors of herbal medicine use among women seeking care for infertility.

\begin{tabular}{|c|c|c|c|c|c|}
\hline Characteristics & Variables & COR (95\% CL) & $p$ value & $\mathrm{AOR}(95 \% \mathrm{CL})$ & $p$ value \\
\hline \multirow{2}{*}{ Age group } & $<30$ years & 1 & & & \\
\hline & $\geq 30$ years & $1.70(0.90-3.22)$ & 0.099 & - & \\
\hline \multirow{2}{*}{ Religion } & Islam & 1 & \multirow{2}{*}{0.694} & & \\
\hline & Christianity & $0.88(0.47-1.66)$ & & - & \\
\hline \multirow{2}{*}{ Marital status } & Single/separated & 1 & \multirow{2}{*}{0.395} & & \\
\hline & Married/cohabitate & $1.79(0.47-6.90)$ & & - & \\
\hline \multirow{2}{*}{ Type of marriage } & Polygamous & 1 & \multirow{2}{*}{0.640} & & \\
\hline & Monogamous & $0.73(0.19-2.76)$ & & - & \\
\hline \multirow{2}{*}{ Change of partner } & No & 1 & \multirow{2}{*}{0.396} & & \\
\hline & Yes & $1.59(0.55-4.62)$ & & - & \\
\hline \multirow{3}{*}{ Duration of relationship } & $>10 \mathrm{yrs}$ & 1 & & 1 & \\
\hline & $1-5$ yrs & $0.23(0.05-0.96)$ & 0.044 & $0.27(0.04-1.59)$ & 0.147 \\
\hline & $6-10$ yrs & $0.36(0.08-1.59)$ & 0.177 & $0.31(0.06-1.68)$ & 0.173 \\
\hline \multirow{4}{*}{ Tribe } & Others & 1 & & & \\
\hline & Mende & $0.81(0.37-1.78)$ & 0.604 & - & \\
\hline & Temne & $1.09(0.49-2.42)$ & 0.826 & - & \\
\hline & Fullah & $0.31(0.06-1.54)$ & 0.154 & - & \\
\hline \multirow{4}{*}{ Educational status } & Tertiary & 1 & & 1 & \\
\hline & Nonformal & $6.30(2.57-15.46)$ & $<0.001$ & $4.03(1.38-11.76)$ & 0.011 \\
\hline & Primary & $7.33(2.68-20.08)$ & $<0.001$ & $6.23(2.02-19.23)$ & 0.001 \\
\hline & Secondary & $2.01(0.78-5.19)$ & 0.146 & $1.90(0.62-5.85)$ & 0.262 \\
\hline \multirow{2}{*}{ Employment status } & Unemployed & 1 & \multirow{2}{*}{0.953} & & \\
\hline & Employed & $1.02(0.47-2.20)$ & & - & \\
\hline \multirow{2}{*}{ Partner with child/children from previous relationship } & No & 1 & \multirow{2}{*}{0.068} & & \\
\hline & Yes & $1.87(0.96-3.64)$ & & & \\
\hline \multirow{4}{*}{ Household income provider } & Self & 1 & & & \\
\hline & Partner & $0.99(0.19-4.92)$ & 0.988 & - & \\
\hline & Both & $0.71(0.15-3.36)$ & 0.669 & - & \\
\hline & Others & $0.00(0.00)$ & 0.999 & - & \\
\hline \multirow{2}{*}{ Monthly income } & 1-3.5 million Leones & 1 & \multirow{2}{*}{0.001} & 1 & \\
\hline & $<1$ million & $3.65(1.74-7.64)$ & & $1.95(0.70-5.42)$ & 0.202 \\
\hline \multirow{3}{*}{ Distance from health facility } & $>10 \mathrm{~km}$ & 1 & & - & \\
\hline & $<5 \mathrm{~km}$ & $0.15(0.02-1.49)$ & 0.105 & - & \\
\hline & $5-10 \mathrm{~km}$ & $0.24(0.02-2.44)$ & 0.229 & - & \\
\hline \multirow{2}{*}{ Presence of health problems } & No & 1 & & & \\
\hline & Yes & $0.85(0.34-2.12)$ & 0.726 & - & \\
\hline \multirow{2}{*}{ Suffering from other reproductive health problems } & No & 1 & & 1 & \\
\hline & Yes & $2.22(1.15-4.31)$ & 0.018 & $2.57(1.13-5.83)$ & 0.024 \\
\hline Reported emotional torture & No & 1 & 0.353 & - & \\
\hline & Yes & $1.54(0.62-3.80)$ & & - & \\
\hline Barriers to accessing fertility care & No & 1 & & 1 & \\
\hline & Yes & $3.19(1.65-6.16)$ & 0.001 & $1.46(0.61-3.49)$ & 0.400 \\
\hline Visited a traditional medicine practitioner & No & 1 & & 1 & \\
\hline visiter a tia a & Yes & $20.59(2.57-165.24)$ & 0.004 & $20.05(2.10-192.28)$ & 0.009 \\
\hline Duration of infertility & $>24$ months & 1 & & & \\
\hline & $0-24$ months & $0.35(0.12-1.03)$ & 0.056 & - & \\
\hline Previously pregnant & No & 1 & & 1 & \\
\hline & Yes & $2.17(1.14-4.13)$ & 0.018 & $2.32(0.93-5.82)$ & 0.072 \\
\hline
\end{tabular}


TABLE 4: Pattern of herbal medicine use among women seeking infertility care.

\begin{tabular}{|c|c|c|}
\hline Characteristics & Variable & $N(\%)$ \\
\hline \multirow{2}{*}{ The use of herbal medicine to treat your condition in the past twelve months } & Yes & $61(36.5)$ \\
\hline & No & $106(63.5)$ \\
\hline \multirow{2}{*}{ Reason for using herbal medicine $n=61$} & Recommended by friends and family & $57(96.7)$ \\
\hline & Others (recommended by herbal medicine seller) & $2(3.3)$ \\
\hline \multirow{2}{*}{ Awareness of the name of the herbal medicine used, $n=61$} & Yes & $29(47.5)$ \\
\hline & No & $32(52.5)$ \\
\hline If yes, name of herbal medicine, $n=29$ & Rabena (Luffa acutangula) & $29(100)$ \\
\hline Route of administration of herbal medicine, $n=61$ & Orally & $61(100)$ \\
\hline If yes, was it beneficial? $n=61$ & No & $61(100)$ \\
\hline \multirow{2}{*}{ Experienced side effects, $n=61$} & Yes & $7(11.5)$ \\
\hline & No & $54(88.5)$ \\
\hline \multirow{3}{*}{ If yes, type of side effect, $n=7$} & Amenorrhea & $3(42.8)$ \\
\hline & Pruritus & $2(28.6)$ \\
\hline & Rash & $2(28.6)$ \\
\hline \multirow{2}{*}{ Disclosure to healthcare provider } & Yes & $12(19.7)$ \\
\hline & No & $49(80.3)$ \\
\hline \multirow{2}{*}{ If no, reason for nondisclosure, $n=49$} & Health provider did not ask & $25(51.0)$ \\
\hline & Thought it was not necessary & $24(49.0)$ \\
\hline
\end{tabular}

TABLE 5: Perception of herbal medicine use among women seeking care for infertility $(n=167)$.

\begin{tabular}{|c|c|c|c|}
\hline Statements & $\begin{array}{l}\text { Agree } \\
n(\%)\end{array}$ & $\begin{array}{c}\text { Disagree } \\
n(\%)\end{array}$ & $\begin{array}{c}\text { Not sure } \\
n(\%)\end{array}$ \\
\hline Herbal medicines are effective for your condition & $2(1.2)$ & $87(52.1)$ & $78(46.7)$ \\
\hline Herbal medicines are safer than western medicines for your condition & $0(0)$ & $89(53.3)$ & $78(46.7)$ \\
\hline Herbal medicines are natural & $77(46.1)$ & $9(5.4)$ & $81(48.5)$ \\
\hline Herbal medicines are beneficial if recommended by healthcare provider & $44(26.3)$ & $13(7.8)$ & $110(65.9)$ \\
\hline Herbal medicines are beneficial if recommended by traditional medicine practitioner or herbalist & $2(1.2)$ & $46(27.5)$ & $119(71.3)$ \\
\hline Herbal medicines should be integrated into the mainstream healthcare system & $6(3.6)$ & $18(10.8)$ & $143(85.6)$ \\
\hline
\end{tabular}

about risk and benefits of herbal medicine use compared to their highly educated counterparts who are likely to make well informed choices. For the less educated women, their decision to use herbal medicine may have been based on the recommendation from their trusted peers. This speculation is supported by our finding that the decision to use herbal medicine was mainly influenced by the recommendation of friends and family. It may also be due to economic status of herbal medicine users in which those that are less educated are likely to be low income earners and as such may likely seek low cost therapeutic options like herbal remedies. Such proposed explanation seems to be supported by our findings in Tables 2 and 3 in which women with low monthly income and those that are less educated were likely to be associated with herbal medicine use. Similar findings were reported by Addo in Ghana [54]. Our study also revealed that herbal medicine use was more common among those who visited traditional medicine practitioners than those who did not. This is expected due to the fact that traditional medicine practitioners are likely to recommend the use of herbs since it is the mainstay of their therapeutic intervention. We also observed in our study that women with other reproductive health problems were more likely to use herbal medicine compared to those without other reproductive health problems. This means that the use of herbal therapy in this study is not entirely directed at enhancing fertility or treating infertility but treating other reproductive health conditions that may limit women's chance to conceive.

The concurrent use of herbal and allopathic medicine in our study poses a threat to patient safety and fertility treatment outcome due to adverse effects and therapeutic failure as a result of herbal-drug interactions and/or herbal medicine contamination $[55,56]$. Patient safety and treatment outcome are further hampered in that the most cited herbal medicine Rabena (Luffa acutangula) does exhibit abortifacient effect $[57,58]$ which can potentially prevent an infertile woman's quest to give birth. In addition, the risk of adverse effect increases with the fact that the choice to use herbal medicine was greatly influenced by people with low level of knowledge about the safety and efficacy of herbal remedies which is in line with findings from Lebanon [35]. This further strengthens the need for fertility care providers to be knowledgeable about common herbal therapies and always take comprehensive medication history 
of their patients with the aim of detecting potential adverse effects which could undermine the outcome of infertility care being provided. Also, public education and counselling of patients are needed since our study shows a gap in awareness about herbal medicine among users.

We observed in our study that there was a low disclosure rate of herbal medicine use among users. This is in line with similar studies in Uganda [38] and Lebanon [5]. The reasons for nondisclosure were that healthcare providers failed to ask and the thought that it not necessary to divulge such information which resonates with the current literature on the nature of physician-patient communication regarding herbal medicine use in Africa [19, 59]. Other reasons for nondisclosure cited in the literature include fear of health provider's reaction that can potentially undermine care and perceived lack of support and understanding from conventional healthcare providers [60-62]. Effective communication between patients and providers is essential to achieving the desired goal of infertility care, the absence of which can negatively affect patient's treatment outcome. Therefore, healthcare providers should be aware of this and always initiate discussion surrounding use of alternative medical care with their patients that is free of prejudice but based on mutual respect. This will encourage patient to freely discuss with their providers wide varieties of issues including traditional medicine use.

\section{Study Limitations and Strengths}

The following limitations need to be considered when interpreting the results of our study. Our results did not represent the views of infertile women in Sierra Leone since this study was only done in the city. Follow-up studies conducted nationally or in other areas of the Sierra Leone are needed to confirm the consistency of our findings. Also, qualitative studies are required to deeply explore this topic in order to fully understand how nonconventional health approaches interact or interface with infertility care in Sierra Leone. In addition, since interviews were conducted in a conventional healthcare setting, the reported prevalence of herbal medicine use might be an underestimation of the actual utilization rate as there is potential bias towards biomedical care among participants. Nevertheless, our study presents the first empirical evidence of herbal medicine use among women seeking infertility care in Sierra Leone and will help influence policy decisions and mode of practice regarding infertility care in Sierra Leone. For example, our findings will help fertility care providers to identify those who are likely users of herbal medicine. The results of our study also emphasize the need for healthcare providers to routinely include the discussion on herbal medicine use during consultation with their patients and advice appropriately with the aim of promoting a favorable health outcome for their patients. In terms of policy, our study provides evidence for public education and counselling of women on the risks and benefits associated with the use of complementary and alternative health approaches for infertility. Since this is the first ever study on this topic in Sierra Leone, our findings add to the scanty literature surrounding alternative or complementary healthcare and infertility in Africa and Sierra Leone in particular and will help provide the basis for further studies to be conducted in Sierra Leone and other African countries.

\section{Conclusion}

The use of herbal medicine among women seeking care for infertility in Freetown, Sierra Leone, is common. Health professionals providing fertility care should be mindful of the pluralistic health-seeking behavior of patients under their care. It is also essential for them to be knowledgeable about the common herbal medicines used for infertility treatment and to routinely initiate dialogue with patients on their risks and benefits.

\section{Abbreviations \\ TCAM: Traditional complementary and alternative medicine \\ COMAHS-USL: College of Medicine and Allied Health Sciences, University of Sierra Leone.}

\section{Conflicts of Interest}

The authors declare that they have no conflicts of interest.

\section{Acknowledgments}

The authors would like to express their thanks and appreciation to all the women that consented to participate and to the management and staff of the health facilities that provided the enabling environment for data collection.

\section{References}

[1] B. H. K. Luk and A. Y. Loke, "The Impact of Infertility on the Psychological Well-Being, Marital Relationships, Sexual Relationships, and Quality of Life of Couples: A Systematic Review," Journal of Sex \& Marital Therapy, vol. 41, no. 6, pp. 610625, 2015.

[2] W. Cates Jr., T. M. M. Farley, and P. J. Rowe, "Infections, pregnancies, and infertility: Perspectives on prevention," Fertility and Sterility, vol. 47, no. 6, pp. 964-968, 1987.

[3] M. N. Mascarenhas, S. R. Flaxman, T. Boerma, S. Vanderpoel, and G. A. Stevens, "National, regional, and global trends in infertility prevalence since 1990: a systematic analysis of 277 health surveys," PLoS Medicine, vol. 9, no. 12, Article ID e1001356, 2012.

[4] W. Ombelet, I. Cooke, S. Dyer, G. Serour, and P. Devroey, "Infertility and the provision of infertility medical services in developing countries," Human Reproduction Update, vol. 14, no. 6, pp. 605-621, 2008.

[5] R. Sembuya, "Mother or nothing: the agony of infertility," Bull World Health Organ, vol. 88, pp. 881-882.

[6] M. Hollos and U. Larsen, "Motherhood in sub-Saharan Africa: The social consequences of infertility in an urban population in northern Tanzania," Culture, Health and Sexuality, vol. 10, no. 2, pp. 159-173, 2008. 
[7] M. Patel, "The socioeconomic impact of infertility on women in developing countries," Facts, Views and Vision in Obstetrics and Gynaecology, vol. 8, no. 1, pp. 59-61, 2016.

[8] S. J. Dyer and M. Patel, "The economic impact of infertility on women in developing countries a systematic review," Facts, Views and Vision in Obstetrics and Gynaecology, vol. 4, no. 2, pp. 102-109, 2012.

[9] R. D. Nachtigall, "International disparities in access to infertility services," Fertility and Sterility, vol. 85, no. 4, pp. 871-875, 2006.

[10] M. C. Inhrorn and P. Patrizio, "Infertility around the globe: new thinking on gender, reproductive technologies and global movements in the 21st century," Human Reproduction Update, 2015.

[11] J. T. F. Lau, Q. Wang, Y. Cheng, J. H. Kim, X. Yang, and H. Y. Tsui, "Infertility-related perceptions and responses and their associations with quality of life among rural Chinese infertile couples," Journal of Sex \& Marital Therapy, vol. 34, no. 3, pp. 248-267, 2008.

[12] S. J. Dyer, N. Abrahams, M. Hoffman, and Z. M. Van Der Spuy, "Infertility in South Africa: Women's reproductive health knowledge and treatment-seeking behaviour for involuntary childlessness," Human Reproduction, vol. 17, no. 6, pp. 16571662, 2002.

[13] S. J. Dyer, "The value of children in African countries - Insights from studies on infertility," Journal of Psychosomatic Obstetrics \& Gynecology, vol. 28, no. 2, pp. 69-77, 2007.

[14] T. Gerrits and M. Shaw, "Biomedical infertility care in subSaharan Africa: a social science review of current practices, experiences and view points," Facts, Views and Vision in Obstetrics and Gynaecology, vol. 2, no. 3, pp. 194-207, 2010.

[15] L. Ibisomi and N. N. Mudege, "Childlessness in Nigeria: perceptions and acceptability," Culture, Health and Sexuality, vol. 16, no. 1, pp. 61-75, 2014.

[16] D. B. Dunson, D. D. Baird, and B. Colombo, "Increased infertility with age in men and women," Obstetrics \& Gynecology, vol. 103, no. 1, pp. 51-56, 2004.

[17] V. Hörbst, "You need someone in a grand boubou," in barriers and means to access ARTs in West Africa Facts Views Vis OBGYN Monogr, pp. 46-52.

[18] S. W. Ndegwa, "Affordable ART in Kenya: The only hope for involuntary childlessness," Facts, Views and Vision in Obstetrics and Gynaecology, vol. 8, no. 2, pp. 128-130, 2016.

[19] I. A. Kretchy, F. Owusu-Daaku, and S. Danquah, "Patterns and determinants of the use of complementary and alternative medicine: a cross-sectional study of hypertensive patients in Ghana," BMC Complementary and Alternative Medicine, vol. 14, article 44, 2014.

[20] P. B. James, A. J. Bah, and I. M. Kondorvoh, "Exploring self-use, attitude and interest to study complementary and alternative medicine (CAM) among final year undergraduate medical, pharmacy and nursing students in Sierra Leone: A comparative study," BMC Complementary and Alternative Medicine, vol. 16, no. 1, article no. 121, 2016.

[21] D. Asfaw Erku and A. Basazn Mekuria, "Prevalence and Correlates of Complementary and Alternative Medicine Use among Hypertensive Patients in Gondar Town, Ethiopia," EvidenceBased Complementary and Alternative Medicine, vol. 2016, Article ID 6987636, 2016.

[22] J. O. Bamidele, W. O. Adebimpe, and E. A. Oladele, "Knowledge, attitude and use of alternative medical therapy amongst urban residents of Osun State, Southwestern Nigeria," African Journal of Traditional, Complementary and Alternative Medicines, vol. 6, no. 3, pp. 281-288, 2009.

[23] A. Gari, R. Yarlagadda, and M. Wolde-Mariam, "Knowledge, attitude, practice, and management of traditional medicine among people of Burka Jato Kebele, West Ethiopia," Journal of Pharmacy and Bioallied Sciences, vol. 7, no. 2, pp. 136-144, 2015.

[24] J. L. E. Onyiapat, I. L. Okoronkwo, and N. P. Ogbonnaya, "Complementary and alternative medicine use among adults in Enugu, Nigeria," BMC Complementary and Alternative Medicine, vol. 11, article 19, 2011.

[25] G. D. Hughes, O. M. Aboyade, R. Beauclair, O. N. Mbamalu, and T. R. Puoane, "Characterizing Herbal Medicine Use for Noncommunicable Diseases in Urban South Africa," EvidenceBased Complementary and Alternative Medicine, vol. 2015, Article ID 736074, 2015.

[26] E. O. Opara and KK., "Factors Affecting Utilization of Herbal Medicine as Livelihood Alternatives among Residents of Imo State: The Role of Social Work Professionals," Journal of Humanities and Social Science, vol. 21, no. 5, pp. 66-78, 2016.

[27] W. Birhan, M. Giday, and T. Teklehaymanot, "The contribution of traditional healers' clinics to public health care system in Addis Ababa, Ethiopia: a cross-sectional study," Journal of Ethnobiology and Ethnomedicine, vol. 7, article 39, 2011.

[28] T. Diaz, A. S. George, S. R. Rao et al., "Healthcare seeking for diarrhoea, malaria and pneumonia among children in four poor rural districts in Sierra Leone in the context of free health care: Results of a cross-sectional survey," BMC Public Health, vol. 13, no. 1, article no. 157, 2013.

[29] S. Ranasinghe, R. Ansumana, J. M. Lamin et al., "Herbs and herbal combinations used to treat suspected malaria in Bo, Sierra Leone," Journal of Ethnopharmacology, vol. 166, pp. 200204, 2015.

[30] P. B. James and A. J. Bah, "Awareness, use, attitude and perceived need for Complementary and Alternative Medicine (CAM) education among undergraduate pharmacy students in Sierra Leone: a descriptive cross-sectional survey," $B M C$ Complementary and Alternative Medicine, vol. 14, article 438, 2014.

[31] P. B. James, H. Kamara, A. J. Bah, A. Steel, and J. Wardle, "Herbal medicine use among hypertensive patients attending public and private health facilities in Freetown Sierra Leone," Complementary Therapies in Clinical Practice, vol. 31, pp. 7-15, 2018.

[32] T. M. Ola, F. O. Aladekomo, and B. A. Oludare, "Determinants of the choice of treatment outlets for infertility in Southwest Nigeria," Rawal Medical Journal, vol. 33, no. 2, pp. 193-196, 2008.

[33] S. K. Bardaweel, M. Shehadeh, G. A. R. Y. Suaifan, and M.-V. Z. Kilani, "Complementary and alternative medicine utilization by a sample of infertile couples in Jordan for infertility treatment: Clinics-based survey," BMC Complementary and Alternative Medicine, vol. 13, article no. 35, 2013.

[34] J.-A. Rayner, H. L. McLachlan, D. A. Forster, and R. Cramer, "Australian women's use of complementary and alternative medicines to enhance fertility: Exploring the experiences of women and practitioners," BMC Complementary and Alternative Medicine, vol. 9, article no. 52, 2009.

[35] G. S. Ghazeeri, J. T. Awwad, M. Alameddine, Z. M. H. Younes, and F. Naja, "Prevalence and determinants of complementary and alternative medicine use among infertile patients in Lebanon: a cross sectional study," BMC Complementary and Alternative Medicine, vol. 12, article 129, 2012. 
[36] J. F. Smith, M. L. Eisenberg, S. G. Millstein et al., “The use of complementary and alternative fertility treatment in couples seeking fertility care: Data from a prospective cohort in the United States," Fertility and Sterility, vol. 93, no. 7, pp. 2169-2174, 2010.

[37] T. Edirne, S. G. Arica, S. Gucuk et al., "Use of complementary and alternative medicines by a sample of Turkish women for infertility enhancement: a descriptive study," BMC Complementary and Alternative Medicine, vol. 10, article 11, 2010.

[38] H. F. Kaadaaga, J. Ajeani, S. Ononge et al., "Prevalence and factors associated with use of herbal medicine among women attending an infertility clinic in Uganda," BMC Complementary and Alternative Medicine, vol. 14, article 27, 2014.

[39] N. Dhont, S. Luchters, W. Ombelet et al., "Gender differences and factors associated with treatment-seeking behaviour for infertility in Rwanda," Human Reproduction, vol. 25, no. 8, pp. 2024-2030, 2010.

[40] P. B. James, A. J. Bah, M. S. Tommy, J. Wardle, and A. Steel, "Herbal medicines use during pregnancy in Sierra Leone: An exploratory cross-sectional study," Women and Birth, 2017.

[41] C. Coulson and J. Jenkins, "Complementary and alternative medicine utilisation in NHS and private clinic settings: a United Kingdom survey of 400 infertility patients," Journal of Experimental \& Clinical Assisted Reproduction, vol. 2, no. 1, article 5, 2005.

[42] M. Stankiewicz, C. Smith, H. Alvino, and R. Norman, "The use of complementary medicine and therapies by patients attending a reproductive medicine unit in South Australia: A prospective survey," Australian and New Zealand Journal of Obstetrics and Gynaecology, vol. 47, no. 2, pp. 145-149, 2007.

[43] WHO, General Guidelines for Methodologies on Research and Evaluation of Traditional Medicine, Geneva WHO: 2000.

[44] A. Bowling, "Mode of questionnaire administration can have serious effects on data quality," Journal of Public Health, vol. 27, no. 3, pp. 281-291, 2005.

[45] J. Adams, G. J. Andrews, J. Barnes, A. Broom, and P. Magin, Traditional, complementary and integrative medicine: an international reader, Macmillan Education, London, UK, 2012.

[46] S. C. Read, M.-E. Carrier, R. Whitley, I. Gold, T. Tulandi, and P. Zelkowitz, "Complementary and alternative medicine use in infertility: Cultural and religious influences in a multicultural canadian setting," The Journal of Alternative and Complementary Medicine, vol. 20, no. 9, pp. 686-692, 2014.

[47] A. Jusu and A. C. Sanchez, "Medicinal Plant Trade in Sierra Leone: Threats and Opportunities for Conservation," Economic Botany, vol. 68, no. 1, pp. 16-29, 2014.

[48] C. A. Macfoy and E. I. Cline, "In vitro antibacterial activities of three plants used in traditional medicine in Sierra Leone," Journal of Ethnopharmacology, vol. 28, no. 3, pp. 323-327, 1990.

[49] J. J. Fledderjohann, "'Zero is not good for me': Implications of infertility in Ghana," Human Reproduction, vol. 27, no. 5, pp. 1383-1390, 2012.

[50] J. Barden-O'Fallon, "Unmet fertility expectations and the perception of fertility problems in a Malawian village," African Journal of Reproductive Health, vol. 9, no. 2, pp. 14-25, 2005.

[51] P. T.-N. Tabong and P. B. Adongo, "Understanding the Social Meaning of Infertility and Childbearing: A Qualitative Study of the Perception of Childbearing and Childlessness in Northern Ghana," PLoS ONE, vol. 8, no. 1, Article ID e54429, 2013.

[52] M. J. Hindin, "Women's autonomy, women's status and fertilityrelated behavior in Zimbabwe," Population Research and Policy Review, vol. 19, no. 3, pp. 255-282, 2000.
[53] D. Quiroz, Do not fear the supernatural!: the relevance of ritual plant use for traditional culture, nature conservation, and human health in western Africa, Wageningen University, 2015.

[54] V. N. Addo, "Herbal Medicines: Socio-Demographic Characteristics And Pattern Of Use By Patients In A Tertiary Obstetrics And Gynaecology Unit," Journal of Science and Technology (Ghana), vol. 27, no. 3, 2008.

[55] S. S. Alwakeel, "Microbial and heavy metals contamination of herbal medicines," Research Journal of Microbiology, vol. 3, no. 12, pp. 683-691, 2008.

[56] C. O. Nwoko and L. Mgbeahuruike, "Heavy metal contamination of ready-to-use herbal remedies in South Eastern Nigeria," Pakistan Journal of Nutrition, vol. 10, no. 10, pp. 959-964, 2011.

[57] H. W. YEUNG, W. W. LI, and T. B. NG, "Isolation of a ribosome-inactivating and abortifacient protein from seeds of Luff a acutangula," International Journal of Peptide and Protein Research, vol. 38, no. 1, pp. 15-19, 1991.

[58] L. C. B. Fernandes, L. A. V. Cordeiro, and B. Soto-Blanco, "Evaluation of the abortifacient effect of Luffa acutangula roxb. in rats," Poisoning by Plants, Mycotoxins, and Related Toxins, pp. 270-273, 2011.

[59] I. A. Lagunju, "Complementary and alternative medicines use in children with epilepsy in Ibadan, Nigeria.," African Journal of Medicine and Medical Sciences, vol. 42, no. 1, pp. 15-23, 2013.

[60] Y. Banda, V. Chapman, R. L. Goldenberg et al., "Use of traditional medicine among pregnant women in Lusaka, Zambia," The Journal of Alternative and Complementary Medicine, vol. 13, no. 1, pp. 123-128, 2007.

[61] S. J. Lubinga, A. Kintu, J. Atuhaire, and S. Asiimwe, "Concomitant herbal medicine and Antiretroviral Therapy (ART) use among HIV patients in Western Uganda: A cross-sectional analysis of magnitude and patterns of use, associated factors and impact on ART adherence," AIDS Care Psychological and Sociomedical Aspects of AIDS/HIV, vol. 24, no. 11, pp. 1375-1383, 2012.

[62] T. R. Puoane, G. D. Hughes, J. Uwimana, Q. Johnson, and W. R. Folk, "Why HIV positive patients on antiretroviral treatment and/or Cotrimoxazole prophylaxis use traditional medicine: Perceptions of health workers, traditional healers and patients: a study in two provinces of South Africa," African Journal of Traditional, Complementary and Alternative Medicines, vol. 9, no. 4, pp. 495-502, 2012. 


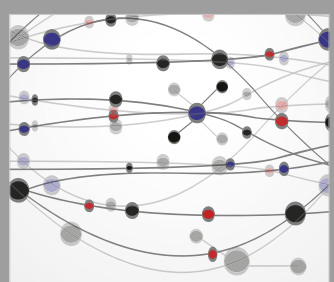

The Scientific World Journal
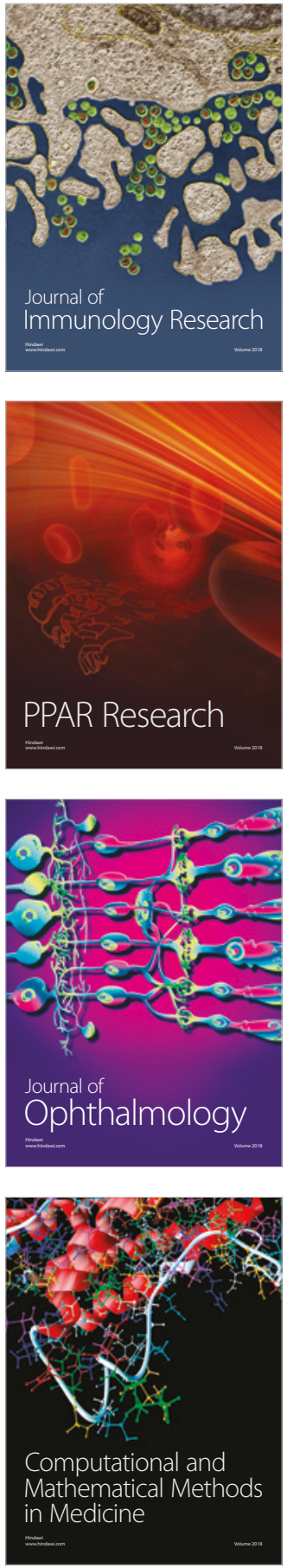

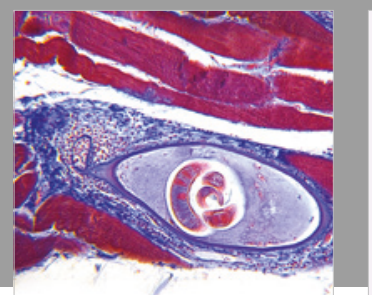

Gastroenterology Research and Practice

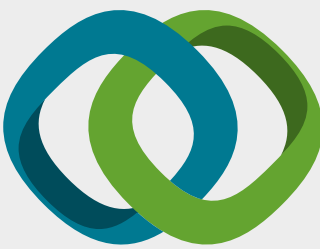

\section{Hindawi}

Submit your manuscripts at

www.hindawi.com
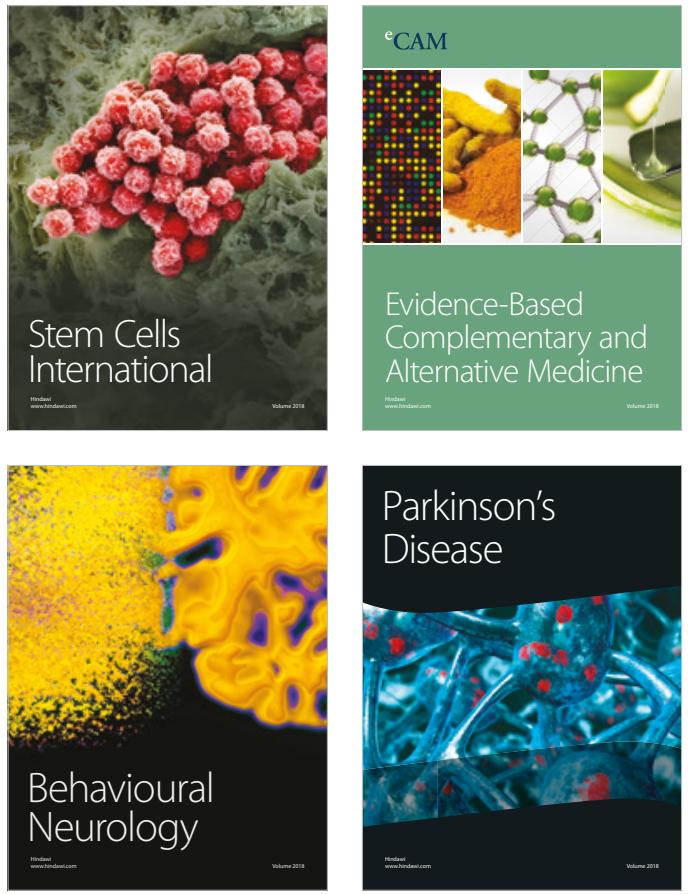

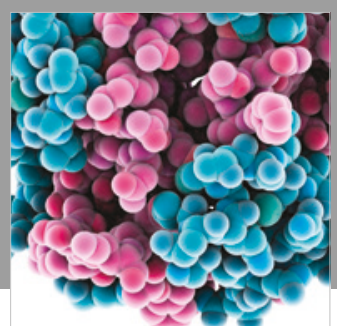

ournal of

Diabetes Research

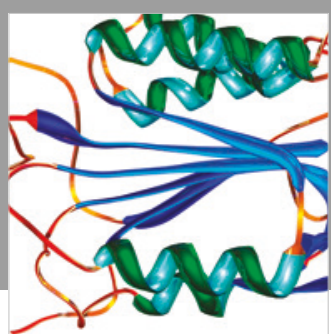

Disease Markers
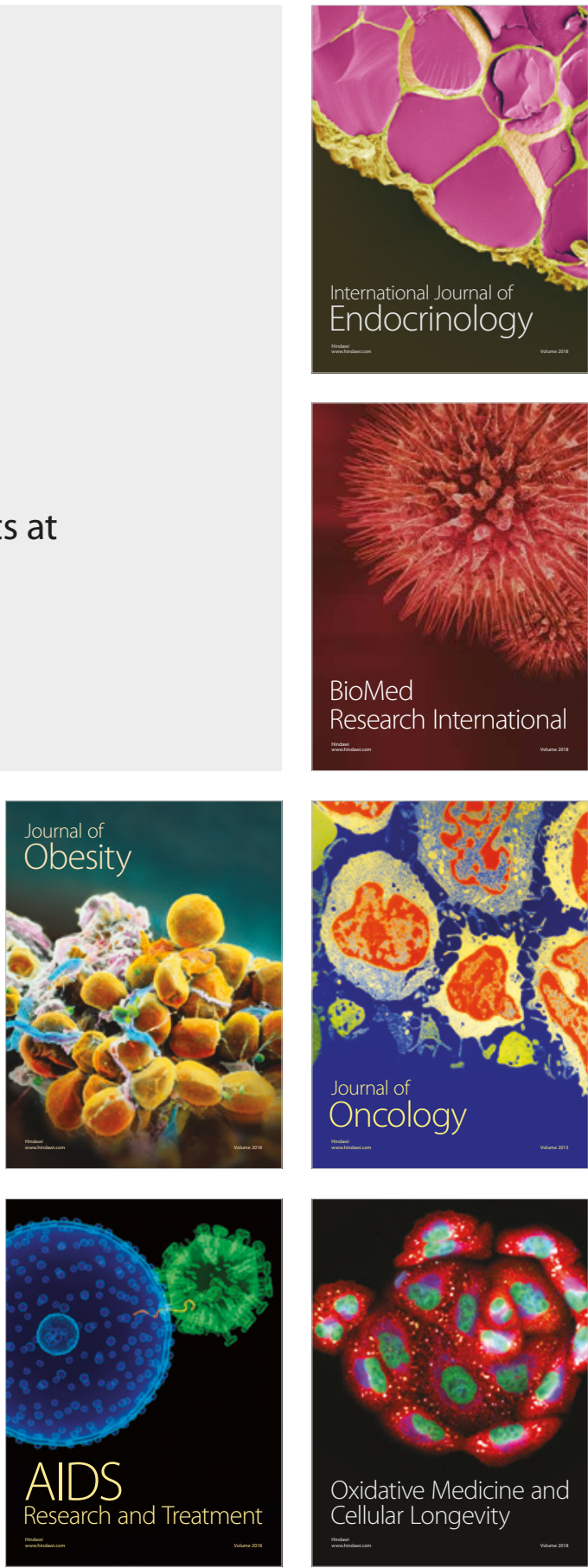